\section{Reinforcement and prior information in the judgment of others' attitudes ${ }^{1}$}

THOMAS M. OSTROM, Ohio State University, Columbus, Ohio 43210, and JEFFREY H. GOLDSTEIN, Temple University, Philadelphia, Pa. 19122

Either pro or anti attitudinal responses were reinforced with "good" under three conditions of prior information regarding the reinforcing agents' (interviewers') attitudes on the issues. For all prior information conditions, the interviewer was viewed as holding a relatively pro attitude when he reinforced pro responses and a relatively anti attitude when he reinforced anti responses.

Perception of the interviewer's (E's) attitude in the verbal reinforcement of attitude responses has been assumed by Insko \& Cialdini (1969) to mediate the effects of a reinforcer such as "good" on attitude change. Reinforcement of discrepant attitudinal responses should lead the $S$ to believe the interviewer personally endorses the discrepant attitude. Attitude should change to the extent that Ss perceive a discrepancy between their initial attitude and that of a likable interviewer.

The present experiment directly tests this hypothesized effect of reinforcement on the perception of the interviewer's attitude. Previous research based on this hypothesis (e.g., Insko \& Cialdini, 1969; Cialdini \& Insko, 1969) has not assessed the magnitude of such S-interviewer discrepancy and its relation to attitude change.

\section{GENERAL DESIGN}

Prior information about the interviewer's attitude and direction of reinforcement were manipulated in a 3 by 2 factorial design. Perception of interviewer's attitude and attitude change were assessed.

Female students in introductory psychology at Ohio State University volunteered to participate in an experiment on "interviewing procedures." Of the $92 \mathrm{Ss}$ reporting for the experiment, the data for two were discarded because of failure to follow instructions.

The Ss reported to a waiting room in which there was a male confederate posing as another $\mathrm{S}$. After several minutes, during which the confederate behaved in a friendly manner, they were called in to the laboratory. They were then separated and asked to complete a questionnaire consisting of 10 pairs of self-descriptive adjectives and 7 attitude items. This questionnaire later served as the basis of manipulating prior information and establishing positive attraction between the $S$ and the confederate. Ss were to select the adjective in each pair most descriptive of themselves and to indicate their degree of agreement on an 11-point scale toward each of the attitude statements. One of these statements served as the attitude pretest and read: "I feel that pay television is good and beneficial to society."

Upon collecting the questionnaires, the E provided the $S$ with a brief mimeographed statement about the purpose of the experiment. This statement indicated that the study dealt with interviewing processes and that one of them would be assigned the task of interviewing the other. Since knowledge of one another's opinions was "typical of many true interviewing situations," they would have an opportunity to look over each other's questionnaire before beginning the interview.

\section{Manipulation of \\ Independent Variables}

Prior to exchanging questionnaires, the $E$ fabricated a questionnaire to be given the $S$ which indicated that the confederate's responses were similar to S's on 8 of 10 self-descriptions and on 6 of the 7 attitude statements. This procedure was employed to induce high positive attraction between the two in all conditions and was based on findings that indicate that similarity is a major determinant of attraction (e.g., Byrne \& Clore, 1966).

The seventh attitude item on the questionnaire was used to convey prior information about the confederate's attitude toward-pay TV. For a third of the Ss, the confederate's attitude toward pay TV was checked as extremely favorable (Rating Category 11), for another third, as extremely unfavorable (Rating Category 1), while the remaining third received no information about the confederate's position. This attitude item was removed from the questionnaire in the no-prior-information condition.

To insure that the $S s$ in the two attitude-informed conditions noticed and remembered how the other participant (confederate) described his own attitude toward pay TV, they were directed to especially note his self-rating for that item and to indicate what his "overall attitude toward pay TV" was on a separate rating scale provided by the $E$. Ss in the no-prior-information condition did not receive this instruction.

Prior to looking over the questionnaire, lots were drawn to determine who would be assigned the role of interviewer and who the role of respondent. The drawing was arranged so that the confederate was always the interviewer and the $S$ always the interviewee. They were also told at this point that the topic of the interview was attitude toward pay TV.

The participants were then seated opposite one another and separated by a partition on the table to "eliminate facial gestures and cues which might interfere with the interview." This eliminated all nonauditory cues the confederate might have inadvertently produced. While the confederate was supposedly examining his directions on how to conduct the interview, the $S$ read instructions indicating she would be asked to evaluate her interviewer's performance following the interview.

The confederate read brief instructions to the $S$ which indicated that she was to respond to each interview question by selecting one of four response alternatives: "clearly disagree," "slightly disagree," "slightly agree," or "clearly agree." The interview, adapted from Insko \& Butzine (1967), consisted of 12 statements about pay TV, half worded positively and half negatively.

In the positive direction of reinforcement condition, Ss were reinforced with "good" for agree responses to positively worded statements toward pay TV and for disagree responses to negatively worded statements. In the negative reinforcement condition, the same reinforcement was delivered, but for the opposite responses.

Throughout the experiment, the confederate was not allowed to see any of the materials completed by the $S$. The confederate was kept unaware of the prior-information condition to which his $S$ was assigned, and he did not learn of her reinforcement condition assignment until he actually began administering the interview.

\section{Dependent Measures}

Following the interview the confederate handed a "Self-Report Questionnaire" to the $S$ which contained several attitude questions, including an item on pay TV identical to that used in the pretest.

The $S$ and confederate were again separated and given several forms to complete. Included was an item requesting an estimate of the interviewer's attitude (on a scale identical to that used in reporting his own attitude) and questions permitting assessment of the meaning Ss gave the reinforcement. 
Table 1

Mean Estimate of Interviewer's Attitude as a Function of Prior Information and Direction of Reinforcement

\begin{tabular}{|c|c|c|c|c|}
\hline \multirow{2}{*}{$\begin{array}{c}\text { Direction of } \\
\text { Reinforcement } \\
\end{array}$} & \multicolumn{4}{|c|}{ Prior Information } \\
\hline & Favorable & Unfavorable & None & $\mathbf{M}$ \\
\hline $\begin{array}{l}\text { Positive } \\
\text { Negative }\end{array}$ & $\begin{array}{r}10.07 \\
8.07\end{array}$ & $\begin{array}{l}3.93 \\
3.13\end{array}$ & $\begin{array}{l}5.60 \\
4.07\end{array}$ & $\begin{array}{l}6.51 \\
5.09\end{array}$ \\
\hline $\mathbf{M}$ & 9.07 & 3.53 & 4.84 & 5.81 \\
\hline
\end{tabular}

Table 2

Mean Attitude Change as a Function of Prior Information and Direction of Reinforcement

\begin{tabular}{|c|c|c|c|c|}
\hline \multirow{2}{*}{$\begin{array}{c}\text { Direction of } \\
\text { Reinforcement }\end{array}$} & \multicolumn{4}{|c|}{ Prior Information } \\
\hline & Favorable & Unfavorable & None & $\mathbf{M}$ \\
\hline $\begin{array}{l}\text { Positive } \\
\text { Negative }\end{array}$ & $\begin{array}{l}0.93 \\
0.73\end{array}$ & $\begin{array}{r}0.40 \\
-1.20\end{array}$ & $\begin{array}{r}1.40 \\
-0.60\end{array}$ & $\begin{array}{r}0.91 \\
-0.36\end{array}$ \\
\hline $\mathbf{M}$ & 0.83 & -0.40 & 0.40 & 0.28 \\
\hline
\end{tabular}

\section{RESULTS AND DISCUSSION}

Perceived Interviewer Attitude

The attitude attributed to the interviewer on the post-interview questionnaire was significantly affected by both prior information $(F=31.34$; $\mathrm{df}=2,84 ; \mathrm{p}<.001$ ) and direction of reinforcement $(F=5.86 ; \quad d f=1,84$ $p<.02$ ). Not unexpectedly, prior information had a much greater effect than reinforcement (see Table 1).

The absence of a significant interaction $(\mathrm{F}<1.0)$ was noteworthy. The effect of reinforcement was apparently no less influential when highly explicit independent information was available than when no such information was available. The availability of such prior information did not lead the $S$ to disregard the information independently conveyed through the interviewer's reinforcement behavior.

The Ss didn't fully accept their interviewer's self-description of attitude. It might be expected that when the interviewer described his own attitude as either a " 1 " or an " 11 " and delivered reinforcements consistent with that self-description, Ss would be lead to rate his attitude as " 1 " or " 11 ." Instead, the means were 4.1 and 10.1. Perhaps Ss chose to believe that since the interviewer was so similar to themselves on the other issues, he could not be very deviant on this one.

\section{Attitude Change}

The predicted relationship between perceived location of the interviewer's attitude and attitude change holds only when positive rapport exists between $S$ and interviewer. Ss indicated how much they liked their interviewer on an 11-point scale at the conclusion of the experiment. The typical evaluation was positive, with the mean rating being 7.84 , nearly two scale units toward the favorable end of the scale. Thus, a positive affective bond was successfully established between the $S$ and interviewer. An analysis of variance indicated there were no significant differences in liking between conditions.

Table 2 shows that the effect of reinforcement on attitude change was significant $(F=6.81 ; \mathrm{df}=1,84 ; \mathrm{p}<.02)$ over all three information groups. A positive change score indicates movement toward the favorable end of the scale and negative scores indicate change toward the unfavorable end of the scale. Although the overall prior-information effect was not significant $(F=2.22 ; d f=2,84 ; p<.12)$, a test of the orthogonal contrast between the favorable and unfavorable prior-information conditions was significant $(F=4.25 ; \mathrm{df}=1,84 ; \mathrm{p}<.05)$. For both main effects, Ss changed in the direction of their interviewer's attitude. Absence of an interaction $(F=1.27)$ suggested that the reinforcement influenced attitude as much when prior information was present as when it was absent.

Despite random assignment of $S s$ to conditions, pretest attitudes were found to differ between reinforcement conditions $(p<.02)$. To assess the effects of this potential bias, an analysis of covariance was performed with the attitude posttest as the dependent measure and the pretest as a covariate. The ordinal pattern of adjusted posttest means was identical to that in Table 2.

To the extent that perceived location of interviewer's attitude is the sole determinant of attitude change when positive rapport exists, as proposed by Insko \& Cialdini (1969), the pattern of means should be similar for Tables 1 and 2 . A serious deviation exists for the positive reinforcement, no-prior-information cell. It shows much greater attitude change than would be expected on the basis of Table 1 . The main effect means are, however, in direct correspondence.

To further examine the contribution of judges' location of interviewer's attitude, a discrepancy score was computed for each $S$ reflecting the scale distance between her own pre-interview attitude rating and her post-interview rating of the interviewer's attitude. A significant within-cell correlation $(r=.379 ; \mathrm{df}=78 ; \mathrm{p}<.01)$ was found between this discrepancy and attitude change, with pretest attitude scores partialled out. Although significant, perceived discrepancy does not account for a very large percent of the variance.

The present data provided direct support for the informational implications of delivering "good" as a reinforcer in the verbal reinforcement of attitude. Perceived location of interviewer's attitude is affected by the direction of reinforcement and prior information. Absence of a high within-cell correlation and imperfect correspondence between the cell means of Tables 1 and 2 suggest that variables in addition to information and rapport, the two factors proposed by Insko \& Cialdini (1969), must be considered.

\section{REFERENCES}

BYRNE, D., \& CLORE, G. L., JR. Predicting interpersonal attraction toward strangers presented in three different stimulus modes. Psychonomic Science, 1966, 4, 239-240.

CIALDINI, R. B., \& INSKO, C. A. Attitudinal verbal reinforcement as a function of informational consistency. Journal of Personality \& Social Psychology, 1969, 12, 342-350.

INSKO, C. A., \& BUTZINE, K. W. Rapport, awareness, and verbal reinforcement of attitude. Journal of Personality \& Social Psychology, 1967, 6, 225-228.

INSKO, C. A., \& CIALDINI, R. B. A test of three interpretations of attitudinal verbal reinforcement. Journal of Personality \& Social Psychology, 1969, 12, 333-341.

$$
\text { NOTE }
$$

1. This research was supported in part by a grant from the Mershon Committee on Education in National Security. The authors would like to thank Dallas Cullen, Larry Cunningham, David Poor, and Claude Steele for their assistance with various phases of the research. We are further grateful for the comments made on an earlier draft of the paper by T.C. Brock and A.G. Greenwald. 